\title{
FREQUENCY CONTROL OF ASYNCHRONOUS MOTORS OF LOOMS OF TEXTILE ENTERPRISES
}

\author{
Nurali Pirmatov ${ }^{1}$, Abdullo Panoev ${ }^{2}$ \\ ${ }^{1}$ Tashkent State Technical University named after I.Karimov, Tashkent, Uzbekistan \\ ${ }^{2}$ Bukhara Engineering -Technological Institute, Uzbekistan
}

\begin{abstract}
In article are brought frequency regulation of the asynchronous electric motor and that reach to energy saving itself. Frequency management is energy saving so regulation of the frequency of the rotation of the asynchronous engine are provided increasing coefficient of efficiency and reduction of the loss to powers. Frequency management, asynchronous engine, economy to energy, load, loom, activate current, frequency of the rotation of the engine.
\end{abstract}

\section{Introduction}

Currently, textile enterprises in the country are improving increasingly. The textile industry itself is complex and diverse. One of its largest sectors is yarn production. Along with cotton fiber, the production of chemical fibers is developing in Republic of Uzbekistan. This will further expand the raw material base of the textile industry of the independent Republic and increase the range of products. Currently, the electric motors used in the textile enterprise "RUSHAN TEKS" LLC in Bukhara, one of the textile enterprises in Bukhara region, can be operated in several ways.

\subsection{Weaving looms asynchronous motor control}

For example, during the operation of electric motors of looms and spinning machines in textile enterprises, current surges are generated, which is called the starting current or the current in the braked rotor. The starting current is 5-7 times higher than the rated current, has a short-term effect, after acceleration the current in the electric motor drops to a minimum value. In accordance with existing norms and regulations, various methods of starting are used to reduce the starting current. Alternatively, a number of measures must be taken to stabilize the supply voltage. One of these methods is the method of controlling weaving looms using a frequency converter. Method for regulating the productivity of a loom and a system for its implementation the method is known to us [1].

However, in this method, in the process of commissioning of weaving looms, as well as in the process of operation, the disconnection of a large number of threads, as well as the waste of electricity, leads to the production of products of poor quality and the waste of a lot of time. Also in the production of spiritually weaving loom thread clamps, the weaving loom can be used for the operation of fastening motors directly through the pulley, device for regulating the working out of the base on a loom the method is known to us [2]. The drawback of this method is that in the process of weaving a weaving machine, that is, there is a lot of thread break during the operation of the weaving machine, as well as during the operation of the start, that is, in the process of commissioning, three to four times more electricity is consumed from its current in the engine and [3]. The engine is starting with loading, the product that is being produced, that is, as a result of the disconnection of woven threads in some places of the burlap.

\subsection{Materials and methods}

Plumb old forklifts asynchronous motor mechanic characteristic calculator analytics cyclic method. The mechanical characteristic of the engine, calculated in this method, differs from the natural characteristic by $4,8 \%[4]$.

\subsection{Results}

The start-up and control of the loom is done by means of a frequency converter, which is set between the automaton and the motor and is controlled by the rotational frequency of the motor, which in addition leads to energy savings. Fig. 1 shows the implementation of the proposed method as a schematic [3]. In accordance with existing norms and regulations, various methods of starting are used to reduce the starting current. Alternatively, a number of measures must be taken to stabilize the supply voltage. One of these methods is the method of controlling the speed of asynchronous motors of looms using a frequency converter. Aim of this measure is to start and control the asynchronous motors of the loom by means of a frequency converter, which is set between the automaton and the asynchronous motor and 
controls the rotational frequency of the asynchronous motor, leading to additional energy savings[4]. Fig. 1 shows a schematic of the implementation of the proposed method[1].

In Fig. 1, there is a closed scheme of frequency control of weaving looms of the textile enterprise "RUSHAN TEKS" LLC in Bukhara, Bukhara region with the help of asynchronous motor[20].

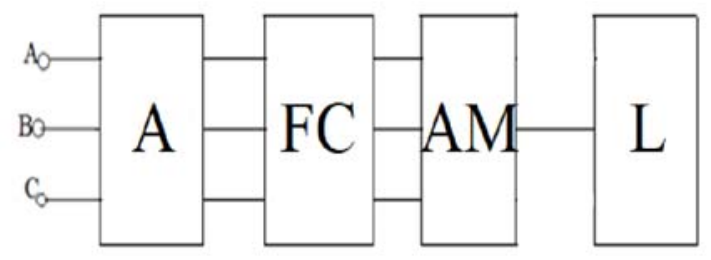

Figure 1. Closed scheme of frequency control of looms by means of asynchronous motor

\section{A- Automaton}

FC- Frequency converter

AM- Asynchronous motor

L - Loom

One of the most commonly used electric motors in looms is asynchronous motors. The electromagnetic moment of an asynchronous machine is interacting with the rotating field generated by the stator winding of the current component $\left(\mathrm{I}_{2} \cos \psi_{2}\right)$ passing through the conductors of the rotor winding, i.e. with the magnetic flux $\Phi_{\max }$ and creates electromagnetic force $\mathrm{F}_{\mathrm{em}}=\mathrm{B}_{\delta} l i$ according to Ampere's law[5].

The electromagnetic moment generated by this force is determined as follows:

$$
M=C_{\mathrm{M}} \cdot \Phi_{\max } \cdot I_{2} \cdot \cos \psi_{2},(1.1)
$$

where:

$$
C_{\mathrm{m}}=p \cdot m_{2} \cdot k_{c h 2} / \sqrt{2}-\text { constant value; }
$$$$
\Phi_{\max }-\text { maximum value of the magnetic flux. }
$$

This formula establishes the relationship between the torque value and the physical events that occur in the motor. It is convenient to use in qualitative analysis of the motor operation in different modes. However, the quantities included in this formula $(\Phi$ $\max , I_{2}$ and $\cos \psi_{2}$ ) are not directly related to the mains voltage and the operating mode of the machine, and this is much more difficult to determine experimentally[4]. Therefore, the simplest determination of the value of the electromagnetic (rotational) torque below can be determined using another formula that allows to take into account the effect of various parameters and operating modes of the machine[12]. The equations of asynchronous machines are derived from the generalized machine equations. In steady state, the equilibrium equation of machine voltages is as follows[20].

$$
\left.\begin{array}{l}
\dot{U}_{s \alpha}=R_{s} \dot{I}_{s \alpha}+j \omega L_{s} \dot{I}_{s \alpha}+j \omega M \dot{I}_{r \alpha}, \\
\dot{U}_{s \beta}=R_{s} \dot{I}_{s \beta}+j \omega L_{s} \dot{I}_{s \beta}+j \omega M \dot{I}_{r \beta,} \\
-\dot{U}_{r \alpha}=R_{r} \dot{I}_{r \alpha}+j \omega L_{r} \dot{I}_{r \alpha}+j \omega M \dot{I}_{s \alpha}+M \dot{I}_{s \beta} \omega_{r}+L_{r} \dot{I}_{r \beta} \omega_{r}, \\
-\dot{U}_{r \beta}=R_{r} \dot{I}_{r \beta}+j \omega L_{r} \dot{I}_{r \beta}+j \omega M \dot{I}_{s \beta}+M \dot{I}_{s \alpha} \omega_{r}+L_{r} \dot{I}_{r \alpha} \omega_{r},
\end{array}\right\}
$$

Where $\dot{U}_{s \alpha}, \dot{U}_{s \beta}, \dot{U}_{r \alpha}, \dot{U}_{r \beta}$ - voltages in the stator and rotor windings along the axes $\alpha$ and $\beta$ accordingly; $\omega_{r}$ - angular speed of the rotor;

$\dot{I}_{s \alpha}, \dot{I}_{s \beta}, \dot{I}_{r \alpha}, \dot{I}_{r \beta}$-currents in the stator and rotor windings along the axes $\alpha$ and $\boldsymbol{\beta}$ accordingly;

$R_{s}, \quad R_{r}$ - active resistances of stator and rotor windings;

$\boldsymbol{L}_{s}, \boldsymbol{L}_{r}$ - scattering inductance of stator and rotor windings;

$M$ - mutual inductance;

$j$ - moment of inertia.

For short-circuited asynchronous mac

$$
\begin{aligned}
& \dot{U}_{r \alpha}=0 ; \\
& \dot{U}_{r \beta}=0 ; \\
& j \omega L_{s}=j \omega M M+j \omega l_{s \sigma} ; \\
& j \omega L_{r}=j \omega M+j \omega l_{r \sigma} ; \\
& x_{0}=\omega M \\
& x_{s}=\omega l_{s \sigma} ;
\end{aligned}
$$

Taking into account $x_{r}=\omega l_{r \sigma}$ and relative speeds $v=\omega_{r} / \omega_{s}$ equation of equilibrium of asynchronous machine voltages has the following form[16].

$$
\left.\begin{array}{l}
\dot{U}_{s \alpha}=R \dot{I}_{s \alpha}+j x_{s} \dot{I}_{s \alpha}+j x_{0} \dot{I}_{s \alpha}+j x_{0} \dot{I}_{s \alpha}, \\
\dot{U}_{s \beta}=R \dot{I}_{s \beta}+j x_{s} \dot{I}_{s \beta}+j x_{0} \dot{I}_{s \beta}+j x_{0} \dot{I}_{s \beta}, \\
0=-R_{r} \dot{I}_{r a}-j x_{r} \dot{I}_{r \alpha}-j x_{0} \dot{I}_{r a}-j x_{0} \dot{I}_{s \alpha}+x_{0} \dot{I}_{r \beta} v+\left(x_{r}+x_{0}\right) \dot{I}_{r \beta} v, \\
0=-R_{r} \dot{I}_{r \beta}-j x_{r} \dot{I}_{r \beta}-j x_{0} \dot{I}_{r \beta}-j x_{0} \dot{I}_{s \beta}+x_{0} \dot{I}_{r \alpha} v+\left(x_{r}+x_{0}\right) \dot{I}_{r \alpha} v .
\end{array}\right\}
$$

Taking into account, $\quad \dot{I}_{s \beta}=j \dot{I}_{s \alpha}$, $\dot{I}_{r \beta}=j \dot{I}_{r \alpha}$ and after the intermediate changes we have the following equations.

$$
\left.\begin{array}{l}
\dot{U}_{s}=R_{s} \dot{I}_{s}+j x_{s} \dot{I}_{s}+j x_{0} \dot{I}_{0}, \\
0=-R_{r} \dot{I}_{r}-j x_{r}(l-v) \dot{I}_{r}-j x_{0}(l-v) \dot{I}_{r}-j x_{0}(l-v) \dot{I}_{s}, \\
\dot{I}_{0}=\dot{I}_{s}+\dot{I}_{r} .
\end{array}\right\}
$$

By bringing the rotor winding to the stator winding and taking into account the slip

$$
S=\frac{\omega_{c} \pm \omega_{r}}{\omega_{c}}=1 \pm v,
$$

After the replacements $\dot{E}_{\mathbf{O}}=-\dot{I}_{\mathbf{O}}{ }^{z_{\mathbf{O}}}$ and $\dot{E}_{\boldsymbol{S}}=\dot{E}_{\boldsymbol{r}}=\dot{E}_{\mathbf{O}} \quad$ we have the following equation for asynchronous machine:

$$
\begin{aligned}
& \dot{U}_{s}=-\dot{E}+\dot{I}_{s} z_{s}, \\
& 0=\dot{E}_{0}-\dot{I}_{r}^{\prime} z_{r}-\dot{I}_{r}^{\prime} R_{r}^{\prime}(1-s) / s \\
& \dot{I}_{\mathrm{O}}=\dot{I}_{s}+\dot{\boldsymbol{Y}}_{r}^{\prime}, \quad(1.7)
\end{aligned}
$$

The equation (1.3) for the stator winding can be written as follows[18]. 


$$
\left.\begin{array}{l}
U_{s \alpha}=d \Psi_{s \alpha} / d t-w_{s} \Psi_{s \beta}+R_{s} I_{s \alpha} \\
U_{s \beta}=d \Psi_{s \beta} / d t-w_{s} \Psi_{s \alpha}+R_{s} I_{s \beta}
\end{array}\right\}
$$

For the rotor winding:

$\left.\begin{array}{l}0=d \Psi_{r \alpha} / d t-\left(w-w_{s}\right) \Psi_{r \beta}+R_{r} I_{r \alpha} \\ 0=d \Psi_{r \beta} / d t-\left(w-w_{s}\right) \Psi_{r \alpha}+R_{r} I_{r \beta}\end{array}\right\}$

Rotor motion equation

$$
\frac{d w_{r}}{d t}=\frac{P}{j}\left(M_{\ni \mathrm{M}}-M_{r}\right)
$$

Electromagnetic moment of asynchronous motor

$$
M_{\text {э. }}=\frac{m_{1} \cdot U_{\text {lnom }}^{2}}{\omega_{1 \text { nom }}} \cdot \gamma^{2} \cdot \frac{1}{[a \cdot(\alpha)]^{2} \cdot \frac{\beta}{r_{2}}+[b \cdot(\alpha)]^{2} \cdot \frac{r_{2}}{\beta}+2 \cdot r_{1} \cdot \alpha}
$$

where $\alpha=\frac{\omega_{1}}{\omega_{1 \text { nom }}}=\frac{f_{1}}{f_{1 \text { nom }}}$ - relative frequency of the stator;

$$
\beta=\frac{\omega_{2}}{\omega_{1 \text { nom }}}=\frac{\omega_{1}-\omega}{\omega_{1 \text { nom }}}=\frac{f_{2}}{f_{1 \text { nom }}}
$$

relative frequency of the rotor;

$$
\begin{aligned}
& \gamma=\frac{U_{1}}{U_{1 \text { nom }}} \quad \text { - relative voltage of the stator; } \\
& \mu=\frac{M}{M_{\text {nom }}} \quad \text { - relative moment; } \\
& a=\frac{r_{1}}{r_{2}} .
\end{aligned}
$$

Bringing to the Kloss's formula

$$
M_{\text {วм }}=\frac{2 \cdot M_{\kappa} \cdot\left(1+q \cdot \beta_{\kappa}\right)}{\frac{\beta}{\beta_{\kappa}}+\frac{\beta_{\kappa}}{\beta}+2 \cdot q \cdot \beta_{\kappa}}
$$

where $q=\frac{r_{1} \cdot X^{2} m}{r_{2} \cdot \alpha \cdot Z_{1}{ }^{2}}$

$\beta_{\kappa}=r_{2} \frac{Z_{2} \cdot(\alpha)}{Z_{1}(\alpha) \cdot X_{2}} \quad$ - absolute

critical slip.

Critical moment

$$
M_{c}(\alpha, \gamma)=\frac{m_{1} \cdot U_{\text {1nom }}^{2}}{\omega_{1 \text { nom }}} \cdot \gamma^{2} \cdot \frac{q \cdot \beta_{c}}{2 \cdot r_{1} \cdot \alpha \cdot\left(1+q \cdot \beta_{c}\right)}
$$

Law of asynchronous motor control (MP Kostenko's law)

$$
\begin{aligned}
& \gamma=\alpha \cdot \sqrt{\mu}, \\
& \frac{U}{U_{\text {nom }}}=\frac{f}{f_{\text {nom }}} \cdot \sqrt{\frac{M}{M_{\text {nom }}}}
\end{aligned}
$$

Fig. 2 shows the natural (continuous line) and U/f $=$ const law based frequency controlled (intermittent line) mechanic characteristics of a 4A100L6U3 type short-circuited rotor asynchronous motor with a power of $2.2 \mathrm{~kW}$, a voltage of $220 / 380 \mathrm{~V}$ and a rotational speed of $950 \mathrm{rpm}$, used in looms[14].

\subsection{Mechanical characteristics of the asynchronous motor}

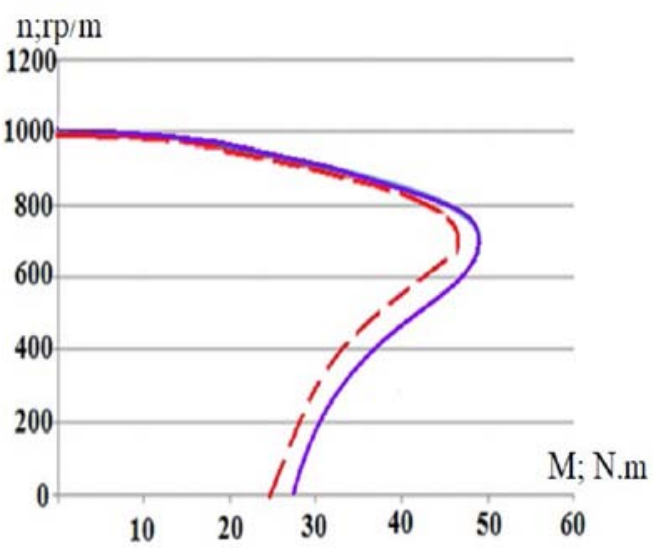

Fig. 2. Mechanical characteristics of 4A100L6U3 type short-circuited rotor asynchronous motor: natural (continuous line) and frequency-controlled mode (intermittent line) [20].

From Fig. 2 it can be seen that the mechanical characteristics of the asynchronous motor in the frequency control mode are very close to the natural mechanical characteristics[16].

The following defects were prevented during the control of the loom using a frequency converter:

1. The yarns do not break, in result some nonwoven areas are woven as well.

2. Prevents the back threads from hanging without twisting with the body threads, i.e. ensures that they are kept at the same tension (same speed).

3. As a result of hanging the back yarn without twisting the yarn, the breaking of the weaving in short sections, that is, the appearance of several lines in the fabric, the breakage of the yarn is prevented (same tension, that is, the same speed), and the production of quality fabric[17].

We divide the modes of smooth start of electric motors on looms into the following three groups:

- normal mode start time is limited from 10 seconds to 20 seconds, the value of starting currents is $3.5 \mathrm{x} \mathrm{I}_{\text {nom; }}$;

- the heavy mode is characterized by slightly larger inertial moment loads. Starting currents are limited to $4.5 \mathrm{x} \mathrm{I}_{\text {nom, }}$ and acceleration time is 30 seconds;

- very heavy mode implies the presence of very high moments of inertia. The starting currents can 
reach $5.5 \times \mathrm{I}_{\text {nom, }}$ and the acceleration time can be significantly increased from 30 seconds.

Types of smooth start of electric motors of looms:

1. Starting moment regulators control only one phase (single-phase control) of a three-phase asynchronous motor. While such a control method can control the smooth start, it cannot ensure that the starting currents decrease. In fact, the current in the motor windings in the starting moment control is equal to the current in the direct start[20]. However, unlike the direct start method, such current flows in the windings for a long time, so the electric motor can overheat. These types of devices can not be used in drives where the starting currents need to be reduced. They do not ensure the activation of high inertial mechanisms (risk of overheating the engine), as well as the sequential start-up (braking) of the electric drive[14].

2. Voltage control without feedback signal. This can only work using a program entered by the user. Due to the lack of feedback from the electric motor, it is not possible to change the motor rotation frequency depending on the changing load. In other cases, such devices meet all the requirements for smooth starting devices, capable of controlling all phases of the electric motor. This type of smooth start device is one of the most common[17]. The motor starting circuit is determined by giving the initial value of the starting voltage and determining the time needed to start. Many devices of this type can be used to limit the inrush current, which is done by reducing the voltage at start[19]. These devices can also be used to control the speed of the electric motor of the loom and to stop the drive slowly. Two-phase regulators can reduce the three-phase voltage of the motor, but the current will be unbalanced.

3. Feedback signal voltage control devices are a modern version of the above-mentioned types of devices. These devices can control the voltage, taking into account the active value of the current, without exceeding the values entered by the user. The obtained data can also be used in the operation of various protection devices (phase imbalance, overload and so on). By combining this type of smooth start of asynchronous motors and similar devices and tools, it is possible to form a unit system that controls the electric motor[15].

\section{Conclusion}

We can say that in the operation of asynchronous electric motors used in textile enterprises, the power consumption in the frequency control of the asynchronous motor is economical, because the frequency converter ensures an adjustment of asynchronous motor speed and increase in coefficient of efficiency of electric drive.

\section{References}

1. Malyutin V. V., Mishinko V.A., Mishinko N.I., Seropyan G. V., Tumanov V. L., Chensov V.P.,
Shaxlin Y V. Material tension control, 1995 .B65H77/00].

2. Stupnikov A.N., Plaksin Y.B., Zimin V.A Regulation of the tension of the base and(or) fabric. Material tension control, 1995. D03D49/04, B65H77/00 .

3.Salimov J,S., Pirmatov N.B. Electric machines.-T.: O'FMJN, 2011,408 p.

4.Berdiyev U.T., Pirmatov N.B. Electromechanics.-T.: Sun ASA, 2014, 391p.

5.Sorkind M. Asynchronous motors 0,4 кВ Emergency modes of operation // Electrical Engineering News. — 2005. — № 2(32).

6.Schneider Electric. Soft start and braking devices Altistart 48. Catalog 2002. ART. 011237RU.

7. Electric drive and automation of industrial installations as a means of energy saving / I.A. Averbax, Y.I. Baras, I.Ya Braslavskiy, Z.Sh. Ishmatov. Yekaterinburg: Sverdlovo Energonadzor, 2002. - 28p

8.Saving fuel and energy resources in the textile industry.Oxotin A. S.M.Legprombytizdat, 1990, 128 p.

9.O.D.Goldenberg. Electric machine testing. M: Higher school. 2000.

10.Brumbach, Michael E. Electronic Variable Speed Drives. Delmar Publishers, 1997.

11.Katzman M.M. Handbook of electric machines: Studies'.stipend.. - Publishing center. « The academy. ", 2005. 480 p.

12.Kopilov I.P. Electric machine. - M.: Yurayt Publishing House., 2012. - 688 p.

13.Lixachev V.L. Asynchronous electric motors.- M.: SOLON -R,2002. -304 p.

14.Xashimov F.A, Modes and indicators of power consumption of textile industry enterprises. Tashkent. «Board»,1986y.

15.Iliniskiy N.F., Rojanovskiy Yu V.,Gornov A.O. Energy savings in the electric drive. - M.: H. sch, 2000. - 127 p.

16.Xashimov A.A., Aripov N.M. Frequencycontrolled asynchronous electric silk winding drive. Monograph. - Tashkent.: TSTU,.

17.Shreyner R.T. Mathematical modeling of AC electric drives with semiconductor frequency converters. Yekaterinburg.: URO RAS.,2000.-654 p. 18. Electric drive and automation of industrial installations as a means of energy saving. / I.A. Averbax, Y.I. Baras, I.Ya. Braslavskiy, Z.SH. Ishmatov. - $\quad$ Yekaterinburg.: $\quad$ Sverdlovo Energonadzor., 2002. -28 p.

19. Energy-saving asynchronous electric drive. // I.Ya. Braslavskiy, Z.SH. Ishmatov., V.N. Polyakov : Studies'. stipend for student. higher. studies'. institutions'. - M.: Publishing center. « The academy», 2004. - $256 \mathrm{p}$.

20.N.B.Pirmatov.,M.G.Axmatov.,N.K.Kamalov.

Investigation of the operation of a synchronous motor with excitation along the longitudinal and transverse axes under shock load. Electricity,2003.м№2-64-65p 